\title{
Apitoxin harvest impairs hypopharyngeal gland structure in Apis mellifera honey bees
}

\author{
Thaís S. Bovi ${ }^{1}$, Paula Onari ${ }^{1}$, Sérgio A. A. Santos ${ }^{2}$, Luis A. Justulin ${ }^{2}$, \\ Ricardo O. ORsI ${ }^{1}$ \\ ${ }^{1}$ Departament of Animal Production, UNESP - Univ Estadual Paulista, Botucatu, Brazil \\ ${ }^{2}$ Department of Morphology, UNESP - Univ Estadual Paulista, Botucatu, Brazil
}

Received 19 December 2016 - Revised 2 May 2017 - Accepted 17 May 2017

\begin{abstract}
Apitoxin harvesting is a stressful practice for honey bees Apis mellifera L. due to the release of alarm pheromones that alter communication and behaviour and may also affect their physiology. Thus, the goal of this research was to verify the effects of apitoxin harvesting on the development of the hypopharyngeal glands (HGs), evaluating the number and area of acini. For this, ten beehives were subjected to one of two treatments: T1, without apitoxin harvest and T2, with apitoxin harvested by an electric collector. We collected ten 6-day-old honey bees in each treatment once every month (October through December). The HGs were removed and were processed for morphological-stereological analysis. The worker bees from hives subjected to treatment $\mathrm{T} 2$ showed a smaller acinar area and lower number of acini than those from hives subjected to treatment T1. Thus, apitoxin harvest negatively affects the structure of the hypopharyngeal glands, consequently affecting the production of royal jelly.
\end{abstract}

\section{apitoxin / beekeeping / hypopharyngeal glands / morphology / nutrition}

\section{INTRODUCTION}

Apitoxin (bee venom) is used by honey bees as a defence mechanism and for colony protection, via signalling by means of alarm pheromones to other bees regarding the presence of a possible enemy and the consequent need for defence (Van der Burg et al. 2014; Danneels et al. 2015). Apitoxin has several identified components, such as mellitin, apamim and phospholipase, for example, toxic to several animal species (Schmidt 1994; Resende et al. 2013). Despite its toxicity, apitoxin has bene-

Corresponding author: R. Orsi, orsi@ fmvz.unesp.br Manuscript editor: Klaus Hartfelder ficial effects on human beings, as biological and antimicrobial effects (Erler and Moritiz 2016).

However, apitoxin harvest by means of an electric collector promotes the release of alarm pheromones, altering the communication and the behaviour of bees by modifying the routine activities, such as the division of labour (Johnson 2003). This harvesting practice can also cause physiological changes in bees, such as damage to the development of the hypopharyngeal glands. This gland produces the protein fraction of royal jelly, which is responsible for the differentiation of caste and is used to feed young larvae and queens (Feng et al. 2009; Kamakura 2011).

The developmental peak of the hypopharyngeal glands is reached when honey bees are 5 to 8 days old (the nurse bee phase) (Deseyn and Billen 2005; Rahman et al. 2014; Omar et al. 2016; Renzi et al. 2016). The size of the gland is related to its activity, and the amount of royal jelly secreted is related to 
the size of the acini. Therefore, developed glands produce more royal jelly (Deseyn and Billen 2005).

Due to the importance of royal jelly for colony nutrition, the goal of this research was to evaluate whether the apitoxin harvest can influence the development of hypopharyngeal glands (area and acini number) in 6-day-old Africanized honey bees, Apis mellifera.

\section{MATERIALS AND METHODS}

\subsection{Treatments}

Ten beehives of Africanized honey bees, A. mellifera L., were used, subjected to one of two treatments: T1, five control beehives, without apitoxin harvesting; and T2, five beehives subjected to apitoxin harvesting. Apitoxin harvest was carried out during 3 months, once each in October, November and December of 2014. Electric collectors were installed in T2 treatment beehives; the apitoxin harvest was performed in the morning, starting at 09:00 and finishing at 10:00 (Modanesi et al. 2015). The effect of the apitoxin harvest was assessed from the developmental cycle of the hypopharyngeal glands of worker bees. According to Deseyn and Billen (2005), the development of glands begins in the prepupal phase and reaches maximal development in the worker bees with 6 days of age; thus, apitoxin harvest was conducted when bees were in the following developmental stages: phase 1: brood comb with 5day-old larvae; phase 2: capped brood (15th day of development)_pupal phase; and phase 3: 3day-old adults honey bees.

\subsection{Collection of honey bees for analysis of hypopharyngeal glands}

Twenty 6-day-old worker bees were collected once a month from the $\mathrm{T} 1$ and $\mathrm{T} 2$ beehives ( $n=10$ /group). For this procedure, capped brood was removed from each beehive; these were then wrapped in tulle fabric to confine the adults after emergence from the brood cells. The brood combs were placed in an incubator with a temperature of $\pm 30{ }^{\circ} \mathrm{C}$ and a humidity of $\pm 60 \%$ until emergence of the adults. The workers that emerged were marked on the pronotum region using a nontoxic pen and then reintroduced to their beehive of origin. After 6 days, four marked worker bees from each beehive, totalling ten worker bees per treatment, were collected using entomological forceps, stored in a plastic container with ventilation holes and subsequently anaesthetised with $\mathrm{CO} 2$ and decapitated with a scalpel. The heads were fixed for $24 \mathrm{~h}$ in $4 \%$ formaldehyde dissolved in 0.1 M phosphate buffer $\mathrm{pH}$ 7.3.

\subsection{Morphology and morphometric analysis of the hypopharyngeal gland}

The methodology for morphometric analysis was adapted from that reported by Smodiš Šker and Gregorc (2010). The heads were dehydrated in a series of ethanol (80,90 and 95\%) for $1 \mathrm{~h}$ each and then embedded in methacrylate resin (HistoResin®, Leica, Heidelberg, Germany). Histological sections of $3 \mu \mathrm{m}$ thickness were cut on rotating microtome and collected on glass slides. The histological sections were stained with haematoxylin and eosin for analysis.

\subsection{Calculation of the mean number and mean area of the secretory acini}

Means of glandular acini number were calculated from 20 histological fields of ten heads per group at $\times 200$ magnification, totalling 200 measurements per group. The histological sections were grouped with spacing of $30 \mu \mathrm{m}$ to avoid that the same acini was measured more than once. Mean acinar area $\left(\mu \mathrm{m}^{2}\right)$ was determined by measuring the all acinar cross-sectional area. Thus, considering the variation of the area of the acini of the hypopharyngeal glands and to avoid misinterpretation, for statistical analysis, only the 100 acini with the highest area of each group were compared.

All analysis was done using a Leica DMLB 80 microscope $(\times 200$ magnification $)$ connected to a 
Leica DC300FX camera. The digitalized images were analysed using Leica Q-win software Version 3 for Windows. The results were expressed as mean \pm standard deviation.

\subsection{Statistical analysis}

The data obtained were analysed using nonparametric Mann-Whitney tests. Differences were
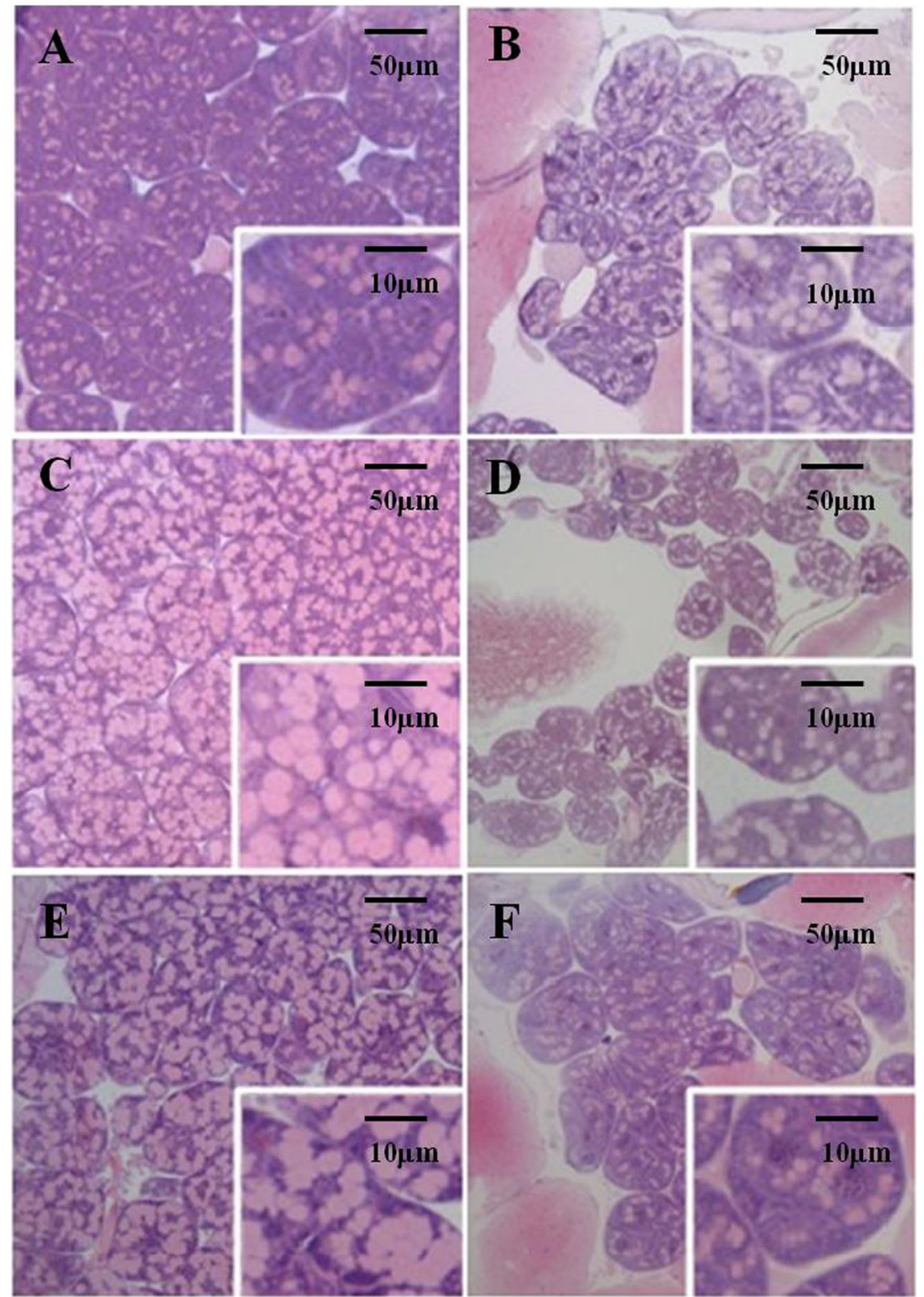

Figure 1. Hypopharyngeal glands of 6-day-old Africanized honey bees Apis mellifera. T1: beehives without apitoxin harvesting and T2: beehives subjected to apitoxin harvesting. a October, T1. b October, T2. c November, T1. d November, T2. e December, T1. f December, T2. Gain: Image 200×, detail 1000×. 
considered statistically significant when $P<0.05$ (Zar 1996).

\section{RESULTS}

Figure $1(\mathrm{a}-\mathrm{f})$ shows the secretory units of the hypopharyngeal glands, represented by multicellular acini. It is apparent that the secretory units of hypopharyngeal glands from bees submitted to apitoxin harvesting (T2) were considerably fewer than those in the control (T1) throughout all 3 months of the study period.

Figure 2 represents the mean number of acini for T1 and T2 throughout the experimental period. The number of acini in $\mathrm{T} 2$ treatment bees was considerably lower than that for $\mathrm{T} 1$ treatment bees in all months of harvesting (October: MannWhitney $U$ test $=1178, P<0.001$; November: Mann-Whitney $U$ test $=1441, P<0.001$; December: Mann-Whitney $U$ test $=2085$, $P<0.001)$.

Figure 3 represents the mean acinar area following treatments $\mathrm{T} 1$ and $\mathrm{T} 2$. Acinar area was smaller in $\mathrm{T} 2$ treatment than in $\mathrm{T} 1$ treatment bees in all months of the harvesting (October: MannWhitney $U$ test $=463, P<0.001$; November: Mann-Whitney $U$ test $=217, P<0.001$; December: Mann-Whitney $U$ test $=700, P<0.001$ ).

\section{DISCUSSION}

The hypopharyngeal glands of honey bees are important for colony development, and the number and area of acini are indicators of their activity, reflecting the amount of protein secretion produced. For this reason, the area of the hypopharyngeal gland acini has been used as an indicator of their development and activity under different management conditions, stresses and nutrition (Babendreier et al. 2005; Smodiš Šker and Gregorc 2010).

During the study period, there was a significant reduction in the number and area of acini in the glands of honey bees subjected to the stress induced by apitoxin harvesting. Thus, this study shows that this practice has a negative effect on the development of the gland, even considering that the period during which the colonies was stressed was short ( $1 \mathrm{~h}$ per month) this is in

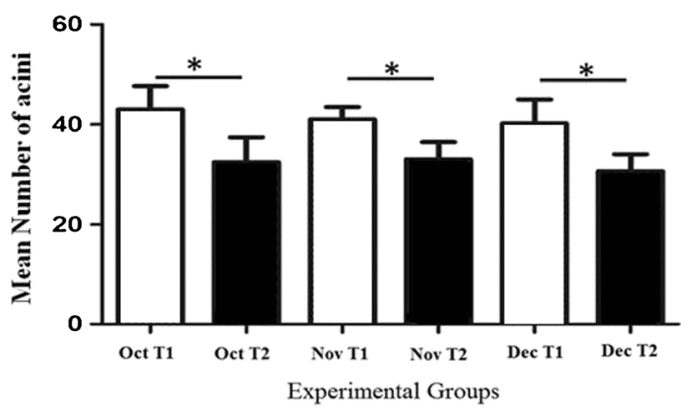

Figure 2. Mean number of acini for treatments T1 and T2, in Africanized honeybees Apis mellifera (October, November and December 2014). T1: beehives without apitoxin harvesting and $\mathrm{T} 2$ : beehives subjected to apitoxin harvesting. The bars show the mean and standard deviation. Asterisks indicate significant differences between groups T1 and T2 for the same month $(P<0.001)$.

accordance with results reported by Modanesi et al. (2015). Onari et al. (2016) showed that the apitoxin harvest impairs the population development of the colonies, also evidencing the negative effects of this management.

The reduction of the hypopharyngeal glands caused by apitoxin harvest could be generated by the stress induced by this management procedure. It is known that this activity stimulates the release of an alarm pheromone (isopentyl acetate), which causes behavioural and

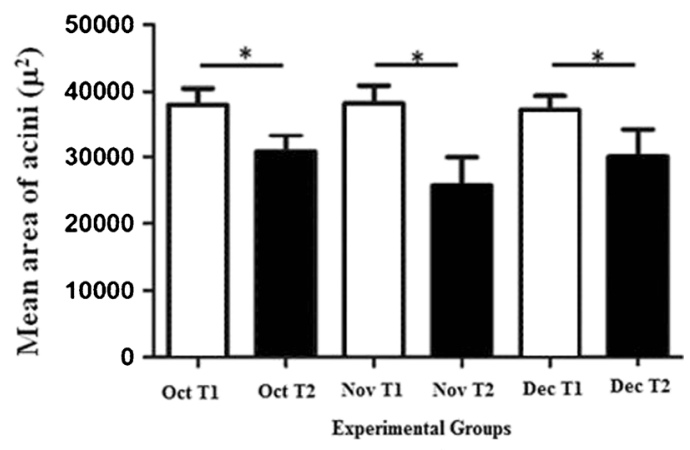

Figure 3. Mean area of acini $\left(\mu \mathrm{m}^{2}\right)$ for treatments $\mathrm{T} 1$ and T2, in Africanized honeybees Apis mellifera (October, November and December 2014). T1: beehives without apitoxin harvesting and T2: beehives subjected to apitoxin harvesting. The bars show the mean and standard deviation. Asterisks indicate significant differences between groups $\mathrm{T} 1$ and $\mathrm{T} 2$ for the same month $(P<0.001)$. 
physiological changes in honey bees. According to Urlacher et al. (2014), isopentyl acetate exerts considerable influence on honey bees during the guard and foraging phases, although it cannot be ruled out that this pheromone has different effects at each age of the bee (Hunt 2007).

Recent research has shown that other types of stressors can also reduce HPGs. Renzi et al. (2016) showed that honey bees fed thiametoxan diet had malformed acini and reduced acinar area. Omar et al. (2016) showed that 1-8-day-old honey bees fed with a mix of pollen or monofloral pollen from Asparagus sp., or Castanea sp. had well-developed HPGS compared to honey bees were fed a $50 \%$ sucrose solution. However, in this research, the honey bees tested were not exposed to contamination by agrochemicals or suffered restrictive diets, confirming that the reduction observed in our study is due to the stress caused by the apitoxin harvesting.

Consequences of the reduction in this gland could be the reduced production of royal jelly and deficient larval feeding (Di Pasquale et al. 2013). In addition, malnourished honey bees may have impaired development, thus reducing their longevity and activities (Li et al. 2014; Perry et al. 2015). It is also possible that the apitoxin harvest can lead to poor quality of royal jelly produced by nurse bees, consequently negatively affecting the feeding of the queen and decreasing the brood area, promoting a vicious cycle that could lead to a gradual reduction in colony size and eventual loss of colonies, though these were not observed in the present study.

Hence, it can be concluded that apitoxin harvest impairs the structure of hypopharyngeal glands of 6-day-old Africanized honey bees Apis mellifera.

\section{ACKNOWLEDGEMENTS}

This work was supported by Fundação de Amparo à Pesquisa do Estado de São Paulo - FAPESP (Process: 2013/25942-9).

La récolte d'apitoxine a un effet négatif sur la structure des glandes hypopharyngiennes chez l'abeille, Apis mellifera
Apiculture / glandes mandibulaires / acini / morphologie / nutrition

Die Bienengiftgewinnung hat negative Auswirkungen auf die Struktur de Hypopharynxdrüsen bei Honigbienen, Apis mellifera

\section{Apitoxin / Bienenhaltung / Hypopharynxdrüsen / Morphologie / Ernährung}

\section{REFERENCES}

Babendreier, D., Kalbere, R.N.M., Romeis, J., Fluri, P., Mulligan, E., Bigler, F. (2005) Influence of Bttransgenic pollen, Bt-toxin and protease inhibitor (SBTI) ingestion on development of the hypopharyngeal glands in honeybees. Apidologie 36, 585-594

Danneels, E.L., Van Vaerenbergh, M., Debyser, G., Devreese, B., Graaf, D.C. (2015) Honeybee venom proteome profile of queens and winter bees as determined by a mass spectrometric approach. Toxins 7 , 4468-4483

Deseyn, J., Billen, J. (2005) Age-dependent morphology and ultrastructure of the hypopharyngeal gland of Apis mellifera workers (Hymenoptera, Apidae). Apidologie 36, 49-57

Di Pasquale, G., Salignon, M., Le Conte, Y., Belzunces, L.P., Decourtye, A., Kretzschmar, A., Suchail, S., Brunet, J., Alaux, C. (2013) Influence of pollen nutrition on honey bee health: do pollen quality and diverse matter? Plos One 8, 1-13

Erler, S., Moritiz, R.F.A. (2016) Pharmacophagy and pharmacophory: mechanisms of self-medication and disease prevention in the honeybee colony (Apis mellifera ). Apidologie. 47, 389-411

Feng, M., Fang, Y., Li, J. (2009) Proteomic analysis of honeybee worker (Apis mellifera) hypopharyngeal gland development. BMC Genomics 10, 645-657

Hunt, G.J. (2007) Flight and fight: a comparative view of the neurophysiology and genetics of honey bee defensive behavior. J. Insect Physiol. 53 (5), 399-410

Johnson, B.R. (2003) Organization of work in the honeybee: a compromise between division of labour and behavioural flexibility. Proc. R. Soc. 270, 147-152

Kamakura, M. (2011) Royalactin induces queen differentiation in honeybees. Nature 473, 478-483

Li, C., Xu, B., Wang, Y., Yang, Z., Yang, W. (2014) Protein content in larval diet affects adult longevity and antioxidant gene expression in honey bee workers. Entomol. Exp. Appl. 151 (1), 19-26

Modanesi, M.S., Kadri, S.M., Ribolla, P.P.E.M., Alonso, D., Orsi, R.O. (2015) Period and time of harvest affects the apitoxin production in Apis mellifera Lineu (Hymenoptera, Apidae) bees and expression of defensin stress related gene. Sociobiology 62 (1), 52-55 
Omar, E., Abd-Ella, A.A., Khodairy, M.M., Moosbeckhofer, R., Crailsheim, K., Brodschneider, R. (2016) Influence of different pollen diets on the development of hypopharyngeal glands and size of acid gland sacs in caged honey bees (Apis mellifera). Apidologie doi:10.1007/s13592-016-0487-X

Onari, P., Zaluski, R., Bovi, T.S., Orsi, R.O. (2016) Apitoxin affects population development but not the hygienic behaviour of African-derived honey bees. Sociobiology 63 (1), 688-692

Perry, C.J., Sovik, E., Myerscough, M.R., Barron, A.B. (2015) Rapid behavioral maturation accelerates failure of stressed honey bee colonies. Proc. Natl. Acad. Sci. U. S. A. 112 (11), 3427-3432

Rahman, S., Thangkhiew, I., Hajong, S.R. (2014) Hypopharyngeal gland activity in task-specific workers under brood and broodless conditions in Apis cerana indica (Fab.). J. Apic. Sci. 58, 61-70

Renzi, M.T., Rodríguez-Gasol, N., Medrzycki, P., Porrini, C., Martini, A., Burgio, G., Maini, S., Sgolastra, F. (2016) Combined effect of pollen quality and thiamethoxan on hypopharyngeal gland development and protein content in Apis mellifera. Apidologie 47, 779-788

Resende, V.M.F., Vasilj, A., Santos, K.S., Palma, M.S., Shevchenko, A. (2013) Proteome and phosphoproteome of Africanized and European honeybee venoms. Proteomics 13, 2638-2648

Schmidt, J.O. (1994) Toxinology of venoms from the honeybee genus Apis . Toxicon 33 (7), 917-927

Smodiš Šker, M.I.S., Gregorc, A. (2010) Heat shock proteins and cell death in situ localization in hypopharyngeal glands of honeybee (Apis mellifera carnica) workers after imidacloprid or coumaphos treatment. Apidologie 41 (1), 73-86

Urlacher, L., Tarr, I.S., Merce, A.R. (2014) Social modulation of stress reactivity and learning in young worker honey bees. Plos ONE 12 (9), 1-17

Van der Burg, N.M.D., Lavidis, N., Claudianos, C., Reinhard, J. (2014) A novel assay to evaluate olfactory modulation of honeybee aggression. Apidologie 45, $478-490$

Zar, J.H. (1996) Bioestatistical analysis. New Jersey: Pretince Hall 